\title{
Chapter 1 What Is Freedom of Speech?
}

It is a well-known fact that the Internet represents a comprehensive and forceful media revolution. In only a few decades, it has connected billions of people all over the world and given them new access to large quantities of information. At the same time, it has put established media and information formats under pressure: newspapers, journals, CDs, radio and TV outlets, movies, books, etc. Still larger parts of the world's marketing budgets migrate from these media to the online tech giants. To a large extent, the survival of established media now depends on whether they are capable of redefining themselves when faced with the Internet-either as dependent on it, by its terms, or as an alternative to it. This also creates new conditions for freedom of speech.

It seems safe to claim that the spirit of the infancy and youth of the Internet as a mainstream platform, in the 1990s and 2000s, was characterized by an optimistic ecstasy with a clear vision of a promising future ahead. The Internet would enlighten the earth's population, connect it in ways that would soften opposition and even out differences. It would create whole new ways for people to practice their freedom of expression and empower them, even spread democracy and freedom across the globe. "Information wants to be free," rejoiced tech-hippie Stewart Brand back in the 1980s. Another incarnation of the same early optimism appeared in 1996, when Grateful Dead lyricist John Perry Barlow published his moving hippie manifesto entitled The Declaration of

F. Stjernfelt, A. M. Lauritzen, Your Post has been Removed, https://doi.org/10.1007/978-3-030-25968-6_1 
Independence of Cyberspace. ${ }^{1}$ In contrast, the 2010s have been a wake-up call. Skepticists, increasingly vocal during the 2000s, turned out to be right; not everything was hunky dory. As more and more people get access to the Internet, it should be no surprise that tensions, strifes and battles of the real world are played out online as well. Manipulation, crime, cold war-not to mention political and religious extremism - have been given new places to unfold, with a full arsenal of completely new tools at their disposal.

Most likely, the years 2016-2018 will be viewed as a decisive watershed to a new and gloomy way of regarding the Internet:

In 2016, the election of Donald Trump as new President of the US was accompanied by high online activity, in which a Russian "troll factory"-Internet Research Agency in Saint Petersburg, Russia-created false Facebook groups with many different extremist agendas. They sent carefully selected voters messages disguised as Twitter messages from American senders. This was a tremendous effort to affect the US elections and gave rise to heated debate on "fake news" and how to fight them. ${ }^{2}$ For obvious reasons, no one can determine to what degree these efforts helped Trump's marginal victory.

In 2017, leading Western nations started seriously discussing regulation of tech giants such as Google, Facebook, Twitter, Amazon, Apple etc. The EU Commission ordered

\footnotetext{
${ }^{1}$ Barlow, J.P. "A Declaration of the Independence of Cyberspace" Electronic Frontier Foundation. 02-08-96.

${ }^{2}$ The concept of "fake news" exploded and quickly degenerated into a swearword used by many to insinuate that their opponents are downright liars. At its core, "fake news" referred to commercial websites (such as nationalreport.net and many others) who produce "fake news" to attract user searches in order to sell adverts - but it also refers to more or less elegantly planted "fake news" material by hostile powers. As early as 2017, one of the inventors of the concept, Craig Silverman, distanced himself from this now watered-down concept-C. Silverman "I Helped Popularize The Term "Fake News" And Now I Cringe Every Time I Hear It" BuzzfeedNews. 12-31-17.
} 
Google to pay a hefty fine for promoting its own products in its search results, Germany adopted its Netzwerkdurchsetzungsgesetz - "Network Implementation Act" - to try to control social media content, highlevel representatives of tech giants appeared in hearings in front of the US Congress and France began to draft its regulatory legislation.

And finally, in 2018 came the revelation of the Cambridge Analytica scandal, where it turned out that a private British consultant company specializing in political analysis, spin and campaign support in a number of countries had gained access to the detailed personal data of 50-90 million Facebook users. ${ }^{3}$ These data had enabled the company, up until the 2016 US presidential election, to very precisely direct their anonymous or pseudonymous voter influence to target selected, undecided voter groups in the decisive US swing states. It is indeed difficult to determine whether there is any truth to ostentatious claims put forward by Cambridge Analytica that the company was in fact architect of the whole Trump campaign, and that it decided the outcome of the US presidential election. These claims were made by the company's top representatives and caught on hidden camera by Channel 4, a British news outlet, whose reporters disguised as Sri Lankan politicians interested in buying similar efforts in order to win their national elections. ${ }^{4}$ This affair put new focus on how tech giants collect user data, both openly and candidly, and how they protect these data and the different ways they use them. In the aftermath, Facebook CEO Mark Zuckerberg himself was summoned to hearings in the US Congress in April 2018 and in the EU Parliament the following month. This period in time witnessed growing inter-

\footnotetext{
${ }^{3}$ Strictly speaking, Cambridge Analytica was a subsidiary of British corporation SCL Group, which had its offices in the United States as a way to circumvent the ban on foreign actors intervening financially in US elections. The company was founded by tech investor Robert Mercer and Breitbart chief editor and Trump campaign leader Steve Bannon.

4"Data, Democracy and Dirty Tricks" Channel4. 03-19-18.
} 
est in the political regulation of tech giants, forcing tech giants to take on a more defensive position, launching - to loud fanfare - a series of changes in attempts to anticipate regulatory measures.

The problems with the Internet are manifold. They include a lack of protection of private data; lack of compliance with copyright legislation; extensive transfer of resources from media actually producing content to platforms simply reproducing said content; creation of huge tech companies which solemnly declare transparency and openness while keeping their internal procedures hidden to the public yet retaining control and ownership in the hands of a tight clique of tycoons in Silicon Valley; the same multinational tech giants' sneaky efforts to minimize their tax payments in tax havens; the Internet's increasing opportunities of international crime, fraud, drugs, child pornography, hacking, extortion etc.; the role of the Internet as a way to communicate with and recruit people for political or religious terrorist movements, oftentimes via the hard-to-control Dark Net; the Internet as a platform for systematic disinformation campaigns and the spread of "fake news"; the Internet as a forum for a new cyber Cold War led by military hackers - just to name a few.

This book does not set out to discuss all these downsides to the brave new online world. We choose one specific area: freedom of expression. This does not mean that we will ignore these other issues - they are all connected. But it does indeed mean that we will embark on an analysis of what the Internet has opened up for in terms of new conditions, possibilities and problems related to free speech.

"Freedom of speech" is itself a hotly debated topic-especially after the heavy debates following the Muhammad cartoon crisis, which began in Denmark in 2006 and put Islamic threats to free speech on the agenda. As a concept, freedom of speech often refers to freedom of speech guaranteed by law, as central parts of the democratic constitutions of many western countries, following the French Declaration of the Rights of Man and of the Citizen of 1789 and the American Bill of Rights of 1791. Both documents acknowledged free- 
dom of speech as one of the basic principles on which to base modern constitutions. This point does not mean, however, that such constitutional protections are absolute. Most countries have exceptions regarding for instance threats, personal defamation, the right to privacy, false product claims - not to mention that certain public officials can renounce their freedom of speech on certain topics. Others have exceptions regarding blasphemy, pornography, "hate speech", etc. But those are nothing more than exceptions, which means that in modern democracies freedom of speech is seen as a fundamental ideal to strive for in legal and political terms and should only be limited by explicit and specifically motivated legislation on specific exceptions.

When it comes to freedom of speech guaranteed by law, a distinction is made between formal and material freedom of speech, according to Danish legal philosopher Alf Ross. The former is concerned with whether a system of censorship is in place -in the absence of censorship before or after the fact, we have formal freedom of speech. ${ }^{6}$ The latter concerns the presence of statements with a particular content, whichonce put forward in the public sphere-can be ruled on post hoc or in some other way treated as crimes. In this sense, no countries can claim to have full freedom of speech-even though a significant decrease is observed in what types of statements are criminalized. As an example, many countries decriminalized blasphemy and pornography during the twentieth century.

This basic understanding of freedom of speech focuses on the government - on how and to what extent it defends the rights of each individual citizen to express him- or herself as he or she wishes. This does not, however, fully cover what one might call "actual" freedom of speech. There are also borderline cases, such as pressure from another state or a terrorist

\footnotetext{
${ }^{5}$ In this book we put "hate speech" in quotation marks to signal that in our opinion it is a vague category which does not refer to any welldefined group of utterances, cf. the review of "hate speech" legislation in Strossen (2018).

${ }^{6}$ Cf. Mchangama \& Stjernfelt (2005) pp. 756ff, 774ff.
} 
group against people who express themselves, be it in the form of violence or threats, for political or religious reasons. Strictly speaking, Iran's 1989 fatwa against author Salman Rushdie, which is still active, is a successful attempt to extend the Iranian jurisdiction to apply to citizens of other nations. It is successful insofar as Iranian agents and sympathizer activists outside Iran have taken it upon themselves to persecute Rushdie in an attempt to carry out the Iranian death sentence which serves, simultaneously, as an instant warning to others who might consider following his footsteps. An example from Denmark is international pressure originating from both Muslim states and Islamist activists. This pressure has indirectly but efficiently forced Danish media to refrain from publishing caricature drawings of the Prophet Muhammad since 2010. This constitutes an actual restriction of Danish freedom of speech, with no regard to the Danish state monopoly on violence or the country's legislation. In a multicultural world, times could lie ahead where jurisdictions of different countries and groups may overlap or collide, resulting in lack of clarity or even conflict as to the limits on freedom of speech.

A third usage of the concept freedom of speech relates to whether there are even media available to spread certain content. During the later years of the absolute monarchy in Denmark, for a long time a few specific publications had the privilege of disseminating political news. For a while Statstidende, the official government journal, even had monopoly on the publication of such news. It meant that no media were allowed to communicate political news or political discussion not acknowledged by the regime. This was government policy - but also other circumstances can cause such restrictions. If for instance all media in a given country, spontaneously or coordinated, agreed to keep out certain content, then there would in fact be no freedom of speech regarding this content, despite the absence of explicit bans on it. If certain media gain in-practice monopoly control on communicating the news, then the editorial policies of said 
media would define the limits of the freedom of speech practiced.

Freedom of speech can also refer to topics broader than the opportunity of individuals or organizations to express themselves freely. It can refer to the right to search for information freely and obtain it freely. In this usage of the concept, the rights holder is not the active and expressing party, but the passive and receiving party. If the media of a given country are strictly controlled-be it control of the formal, material or actual freedom of speech - then the audiences who use these media do not enjoy freedom of speech in this broader understanding of the term (even though these users themselves do not necessarily attempt to practice that expression and are hindered). Thus, the UN's Declaration of Human Rights includes this information search aspect in its article on freedom of expression: "Everyone has the right to freedom of opinion and expression; this right includes freedom to hold opinions without interference and to seek, receive and impart information and ideas through any media and regardless of frontiers." A similar choice of words can be found in the European Convention on Human Rights. This broader understanding of free speech includes anything which might impede the free exchange of information for citizens and civil organizations.

A number of classical freedoms - often referred to as "first generation" human rights-are closely connected to freedom of speech. This goes especially for the freedom of religion or belief, which is the right of individuals to define their faith and affiliation to a religious community. Sometimes this is confounded with libertas ecclesiae, which is when churches call for exemption from certain legislations, but that is an entirely different matter (and possibly in opposition to freedom of speech). The freedom to believe was among the principal motivations behind the fight for freedom of expression in Europe between the seventeenth to nineteenth

\footnotetext{
7"UN Universal Declaration of Human Rights (1948)" Amnesty International.
} 
centuries, and it is still a disputed and restricted right in many countries, for instance in China and the Muslim world. Freedom of the press and freedom of thought are closely related to free speech, and both are often used synonymously with freedom of speech. The same goes for the freedom of assembly and association, which underpin the citizens' right to gather physically and in organizations to share information and points of view.

In the following chapters, we will examine all these aspects of freedom of speech online-and we will do our best to make it clear which forms of this concept we are discussing and when.

Open Access This chapter is licensed under the terms of the Creative Commons Attribution 4.0 International License (http://creativecommons.org/licenses/by/4.0/), which permits use, sharing, adaptation, distribution and reproduction in any medium or format, as long as you give appropriate credit to the original author(s) and the source, provide a link to the Creative Commons license and indicate if changes were made.

The images or other third party material in this chapter are included in the chapter's Creative Commons license, unless indicated otherwise in a credit line to the material. If material is not included in the chapter's Creative Commons license and your intended use is not permitted by statutory regulation or exceeds the permitted use, you will need to obtain permission directly from the copyright holder.

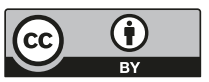

